\title{
Estimating the effect of urease inhibitor on rice yield based on NDVI at key growth stages
}

\author{
Kailou LIU, Yazhen LI (ه), Huiwen HU \\ National Engineering and Technology Research Center for Red Soil Improvement, Jiangxi Institute of Red Soil, Jinxian 331717, China
}

\begin{abstract}
The effect of the urease inhibitor, N-(n-butyl) thiophosphoric triamide (NBPT) at a range of application rates on rice production was examined in a field experiment at Jinxian County, Jiangxi Province, China. The normalized difference vegetation index (NDVI) was measured at key growth stages in both early and late rice. The results showed that the grain yield increased significantly when urea was applied with NBPT, with the highest yield observed at $1.00 \%$ NBPT (wt/wt). NDVI differed with the growth stage of rice; it remained steady from the heading to the filling stage. Rice yield could be predicted from the NDVI taken at key rice growing stages, with $R^{2}$ ranging from 0.34 to 0.69 in early rice and 0.49 to 0.70 in late rice. The validation test showed that RMSE $\left(\mathrm{t} \cdot \mathrm{hm}^{-2}\right)$ values were 0.77 and 0.87 in early and late rice, respectively. Therefore, it was feasible to estimate rice yield for different amounts of urease inhibitor using NDVI.
\end{abstract}

Keywords normalized difference vegetation index (NDVI), N-(n-butyl) thiophosphoric triamide (NBPT), rice, grain yield

\section{Introduction}

Nitrogen fertilizer is an essential input on most farms during crop production. Urea is the most widely used $\mathrm{N}$ fertilizer in the world because of its solubility, high $\mathrm{N}$ concentration and ease of handling, and accounts for over $50 \%$ of all $\mathrm{N}$ applied [1]. However, it is more susceptible to loss as ammonia gas when left on the soil surface. After applying urea to soil, it is rapidly hydrolyzed by urease enzymes to form ammonia. The excess emission of ammonia results in a significant economic loss for farmers and has a negative effect on air quality, crop productivity, and human health $[1,2]$.

$\mathrm{N}$-(n-butyl) thiophosphoric triamide (NBPT) is a urease

Received April 25, 2014; accepted May 24, 2014

Correspondence: liyazhen626@163.com inhibitor which can reduce nitrogen loss via ammonia volatilization from urea and dicyandiamide. It is used as a fertilizer additive in agricultural applications. Once applied to the soil, NBPT can reduce urease activity, slow down the hydrolysis process of urease decomposition, prolong urease diffusion time and decrease the concentration of ammonia present near the soil surface. All these factors reduce the potential for volatilization and allow urea to move deeper into the soil under irrigation or rainfall $[3,4]$. In addition, if applied with urea, NBPT will increase leaf chlorophyll content, plant growth and fiber quality of cotton by improving $\mathrm{N}$ use efficiency and lint yield [5]. Ding et al. found that NBPT increase maize yield from fluvo-aquic soil on the North China Plain. NBPT may also reduce $\mathrm{N}_{2} \mathrm{O}$ emission by decreasing the nitrification and denitrification rate [6]. Dawar et al. found that NBPT had potential in mitigating $\mathrm{N}$ losses, improving $\mathrm{N}$-response efficiency and increasing herbage production in intensive grassland systems [7]. These results showed that applying urea with NBPT could improve crop yield in dryland cropping, but little information is available for paddy rice production. Although urease inhibitors can effectively reduce ammonia loss from urea broadcast into the floodwater of rice fields [8] and increase grain yield, the yield increases from use of inhibitors might be small [9]. The limited yield increase in paddy rice, which is different from dryland production, may be due to the low rates of NBPT applied in previous studies. Therefore, we investigated the yield response under different NBPT application rates to determine the suitable ratio of NBPT and urea.

Spectral determinations provide an automatic, quick and non-destructive way of assessing crop biomass, nutrient status and other crop growth parameters. The normalized difference vegetation index (NDVI) is the function of reflectance of red and near infrared (NIR) bands. It is one of the most extensively applied vegetation indices related to leaf area index, biomass and yield prediction [10-12]. Harrell et al. found NDVI measurements taken after panicle differentiation (PD) and panicle initiation (PI) have the potential to improve mid-season $\mathrm{N}$ crop management 
decisions in rice, and regression analysis produced two viable yield potential prediction equations at PI $\left(R^{2}=0.36\right)$ and PD $\left(R^{2}=0.42\right)$ [13]. Likewise, Saberioon et al. suggested that $\mathrm{N}$ and grain yield were significantly correlated with NDVI $\left(R^{2}=0.78\right)$, especially at the panicle initiation and booting stages [14]. Chen et al. indicated that the canopy spectrum-based nitrogen optimization algorithm is a good technique for optimizing $\mathrm{N}$ application rates in rice, with higher economic benefit, less $\mathrm{N}$ input and better applicability under different base-tiller $\mathrm{N}$ application rates [15]. So, a strong positive correlation between vegetation canopy bidirectional reflectance factor in the near infrared spectral region and foliar mass-based nitrogen concentration could indicate an additional role for nitrogen in the climate system via its influence on surface albedo and may offer a simple approach for monitoring foliar nitrogen using satellite data. However, the previously reported correlation is considered to be an artifact - it is a consequence of variations in canopy structure, rather than of $\mathrm{N}$ concentration [16], because the data underlying this relationship were collected at sites with varying proportions of foliar nitrogen-poor needle leaf and nitrogen-rich broadleaf species, and canopy structure was affected by leaf biochemical constituents and surface characteristics of leaves. Therefore, there is doubt that rice yield can be estimated from NDVI taken at key growth stages. The objectives of this study were (1) to examine the effects of different rates of urease inhibitors on rice yield and (2) to identify the potential for estimating rice yield at key growth stages using NDVI.

\section{Materials and methods}

\subsection{Site description}

The research was conducted in 2012 at the Jiangxi Institute of Red Soil, Jinxian County $\left(116^{\circ} 17^{\prime} 57^{\prime \prime} \mathrm{E}, 28^{\circ} 35^{\prime} 30^{\prime \prime} \mathrm{N}\right.$, $31 \mathrm{~m}$ above sea level), Jiangxi Province, China. This location has a typical subtropical climate with distinct arid (July-September) and humid (March-June) seasons, with a mean annual temperature of $17.2^{\circ} \mathrm{C}$ and rainfall of $1549 \mathrm{~mm}$. The soil developed from a Quaternary red clay. The soil in the experimental plots contained $9.4 \mathrm{~g} \cdot \mathrm{kg}^{-1}$ organic $\mathrm{C}, 0.98 \mathrm{~g} \cdot \mathrm{kg}^{-1}$ total $\mathrm{N}, 0.62 \mathrm{~g} \cdot \mathrm{kg}^{-1}$ total $\mathrm{P}$ and $11.4 \mathrm{~g} \cdot \mathrm{kg}^{-1}$ total $\mathrm{K}$ with a $\mathrm{pH}$ of 6.0 . Experimental plots were $20 \mathrm{~m}^{2}(5 \mathrm{~m} \times 4 \mathrm{~m})$ and validation plots $150 \mathrm{~m}^{2}$ $(30 \mathrm{~m} \times 5 \mathrm{~m})$. All plots were separated with individual irrigation supply and drains.

\subsection{Experimental design}

To investigate the NBPT application rate in rice production, a field experiment with seven treatments was conducted. NBPT was applied at $0.00 \%, 0.50 \%, 0.75 \%$, $1.00 \%, 1.25 \%$ and $1.50 \%$ with urea at $135 \mathrm{~kg} \mathrm{~N} \cdot \mathrm{hm}^{-2}$ plus a control without urea or NBPT. The treated plots were arranged in a randomized complete block with three replications. All plots received $75 \mathrm{~kg} \cdot \mathrm{hm}^{-2} \mathrm{P}_{2} \mathrm{O}_{5}$ (superphosphate, $\mathrm{P}_{2} \mathrm{O}_{5} 12 \%$ ) and $150 \mathrm{~kg} \cdot \mathrm{hm}^{-2} \mathrm{~K}_{2} \mathrm{O}$ (potassium sulfate, $\mathrm{K}_{2} \mathrm{O} 60 \%$ ). Fertilizer and NBPT were applied by broadcast at sowing.

Early rice cv. Denong 88 was sown on 22 March and transplanted on 23 April. Late rice cv. Shanyou 456 was sown on 20 June and transplanted on 24 July. Both were transplanted at 25 hills per $\mathrm{m}^{2}(20 \mathrm{~cm} \times 20 \mathrm{~cm}$ spacing $)$.

\subsection{Spectroradiometer}

NDVI measurements were taken with a Greenseeker Hand Held Optical Sensor Unit (Greenseeker ${ }^{\mathrm{TM}}$ Model 505, NTech Industries, Inc., Ukiah, CA, USA). The wavelengths used were visible (RED, $671 \mathrm{~nm}$ ) and infrared (NIR, $780 \mathrm{~nm}$ ). Half-power bandwidths were about $25 \mathrm{~nm}$. Reflectance values at $671 \mathrm{~nm}\left(R_{R E D}\right)$ and $780 \mathrm{~nm}\left(R_{N I R}\right)$ were used to calculate the NDVI:

$$
\mathrm{NDVI}=\frac{R_{N I R}-R_{R E D}}{R_{N I R}+R_{R E D}}
$$

where NIR and RED denote the reflectance of near infrared and red channels, respectively.

\subsection{Canopy reflectance measurements}

Rice canopy reflectance measurements at $780 \mathrm{~nm}$ (near infrared) and $671 \mathrm{~nm}$ (infrared) and $6 \mathrm{~nm}$ in width were made with the Greenseeker. The Greenseeker was held $45 \mathrm{~cm}$ above the rice canopy under cloudless conditions and as close to solar noon as possible. The measurements were taken at the tillering, booting, heading and filling stages $(30,49,59$ and 69 days after transplanting in early, and $21,36,62$ and 81 days after transplanting in late rice, respectively). Before each measurement, a dark current and a white-panel correction were performed. Ten canopy spectral reflectance measurements were taken in each plot, then averaged.

\subsection{Grain yield}

Three hills were sampled from each plot at maturity. To ensure the representativeness of the sampling, tiller numbers for 50 hills from 3 different locations were counted in each plot before sampling. Based on these tiller numbers, three representative hills were reselected and destructively sampled.

For samples taken at maturity, panicles were handthreshed and the filled spikelets were separated by submerging in water. The filled spikelets were then ovendried at $80^{\circ} \mathrm{C}$ to constant weight for determining 1000 grain weights. Spikelets per panicle, filled grain percentage and spikelets per $\mathrm{m}^{2}$ were calculated. Grain yield was determined for $5 \mathrm{~m}^{2}$ from each plot and adjusted to a 
moisture content of $13.50 \%$.

\subsection{Validation}

To validate the model developed, another field experiment was conducted with six treatments: Vcontrol, no nitrogen fertilizer or no NBPT both in early and late rice; V0.00\% NBPT, $135 \mathrm{~kg} \cdot \mathrm{hm}^{-2}$ nitrogen fertilizer with no NBPT in early and late rice; V0.50\% NBPT, $135 \mathrm{~kg} \cdot \mathrm{hm}^{-2}$ nitrogen fertilizer with $0.50 \%$ NBPT in early and late rice; V1.00\% NBPT, $135 \mathrm{~kg} \cdot \mathrm{hm}^{-2}$ nitrogen fertilizer with $1.00 \%$ NBPT in early rice and late rice; V1.50\% NBPT, $135 \mathrm{~kg} \cdot \mathrm{hm}^{-2}$ nitrogen fertilizer with $1.50 \%$ NBPT in early rice and late rice; and $\mathrm{V} 2.00 \% \mathrm{NBPT}, 135 \mathrm{~kg} \cdot \mathrm{hm}^{-2}$ nitrogen fertilizer with $2.00 \%$ NBPT in early rice and late rice. $\mathrm{P}$ and $\mathrm{K}$ were applied and NDVI measurements were taken as described above. Grain yields for early and late rice in five fields were determined from $20 \mathrm{~m}^{2}$ and adjusted to a moisture content of $13.5 \%$.

The validation of the model was estimated from the $R^{2}$, RER (range error ratio) and RMSE (root mean square error):

$$
\mathrm{RER}=\frac{X_{0}-X_{\mathrm{S}}}{X_{0}} \times 100 \%
$$
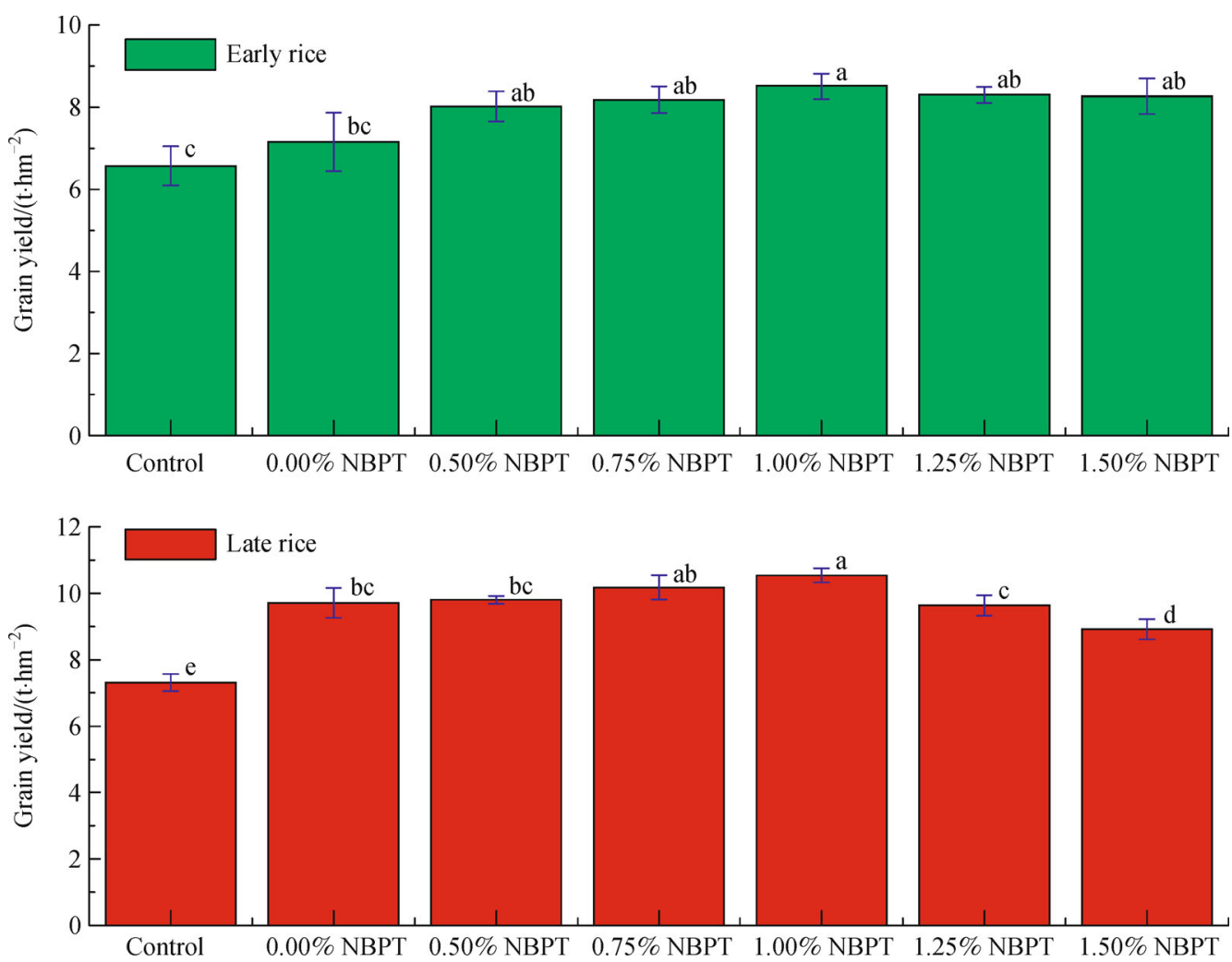

where $X_{0}$ and $X_{\mathrm{S}}$ are the measured and estimated values, respectively.

Analysis of variance (completely randomized design) was perform with SPSS 16.0 with comparison of means between treatments using the Least Significant Difference (LSD) test at $P=0.05$.

\section{Results}

\subsection{Grain yield}

The application of urea increased the grain yield significantly under all NBPT application rates for both early and late rice compared with the control (Fig. 1). The grain yield increased gradually with the increase in NBPT application rate until the urea to uease inhibitor ratio reached $1.00 \%$ NBPT (wt/wt). Above $1.00 \%$ NBPT, the grain yield of early rice remained constant, whereas the yield of late rice decreased significantly. The higher temperatures and rainfall experienced by late rice might have been factors contributing to this result. Nevertheless, 
in both early and late rice $1.00 \%$ NBPT was optimal.

\subsection{Yield components}

Table 1 shows the rice yield components under different NBPT application rates. For early rice, NBPT application had no effect on plant height, panicle number, panicle length, spikelets/panicle, proportion of filled grain and 1000 -grain weight. However, a little reduction of 1000grain weight was observed at $1.25 \%$ NBPT. In addition, NBPT increased the panicle and grain filling compared to the control.

For late rice, NBPT altered the plant height, panicle number, panicle length and spikelets/panicle, but it had no effects on the proportion of grain filling and 1000-grain weight. Compared to the control, the plant height, panicle number, panicle length and spikelet/panicle increased significantly when urea was applied with NBPT (Table 2). The greatest responses in plant height, panicle number and spikelets/panicle were observed at $1.00 \%$ NBPT.

\subsection{NDVI at key growth stages}

NDVI values changed with rice growth stage, with the highest value at the jointing stage in early rice and at the tillering stage in late rice (Fig. 2). For early rice, NDVI increased gradually from the tillering to the jointing stage. It then declined slowly and remained steady during the heading and filling stages. However, NDVI decreased from the tillering to filling stage in the late rice growth season and remained steady from the heading to the filling stage. The NDVI for treatment with urea was significantly higher than in the control (Fig. 2), while there was no significant difference among different NBPT application rates with urea.

\subsection{Relationship between NDVI grain yield}

The grain yield could be predicted from the NDVI values at different growing stages (Table 2). There was an exponential relationship between grain yield and NDVI, with regression coefficient $0.34-0.68$ in early rice and

Table 1 Yield components of rice treated with different concentrations of the urease inhibitor NBPT in conjunction with urea application

\begin{tabular}{|c|c|c|c|c|c|c|}
\hline Treatments & Plant height $/ \mathrm{cm}$ & Panicles $/ \mathrm{m}^{-2}$ & Panicle length/cm & $\begin{array}{l}\text { Spikelets per } \\
\text { Panicle }\end{array}$ & Grain filling/\% & 1000 -grain weight/g \\
\hline \multicolumn{7}{|l|}{ Early rice } \\
\hline Control & $93.33 \mathrm{a}$ & $248.00 \mathrm{~b}$ & $20.48 \mathrm{a}$ & $109.63 \mathrm{a}$ & $90.32 \mathrm{~b}$ & $28.04 \mathrm{ab}$ \\
\hline $0.00 \% \mathrm{NBPT}$ & $96.67 \mathrm{a}$ & $280.00 \mathrm{a}$ & $20.05 \mathrm{a}$ & $100.47 \mathrm{a}$ & $93.68 \mathrm{ab}$ & $27.86 \mathrm{ab}$ \\
\hline $0.50 \% \mathrm{NBPT}$ & $98.67 \mathrm{a}$ & $290.67 \mathrm{a}$ & $20.27 \mathrm{a}$ & $114.82 \mathrm{a}$ & $94.82 \mathrm{a}$ & $27.95 \mathrm{ab}$ \\
\hline $075 \%$ NBPT & $95.17 \mathrm{a}$ & $277.33 \mathrm{a}$ & $20.54 \mathrm{a}$ & $114.17 \mathrm{a}$ & $94.10 \mathrm{a}$ & $28.21 \mathrm{a}$ \\
\hline $1.00 \% \mathrm{NBPT}$ & $95.67 \mathrm{a}$ & $298.67 \mathrm{a}$ & $20.33 \mathrm{a}$ & $112.73 \mathrm{a}$ & $94.64 \mathrm{a}$ & $28.47 \mathrm{a}$ \\
\hline $1.25 \% \mathrm{NBPT}$ & $99.67 \mathrm{a}$ & $290.67 \mathrm{a}$ & $20.84 \mathrm{a}$ & $119.40 \mathrm{a}$ & $95.00 \mathrm{a}$ & $27.18 \mathrm{~b}$ \\
\hline $1.50 \% \mathrm{NBPT}$ & $98.00 \mathrm{a}$ & $288.00 \mathrm{a}$ & $20.23 \mathrm{a}$ & $111.13 \mathrm{a}$ & $94.88 \mathrm{a}$ & $28.47 \mathrm{a}$ \\
\hline \multicolumn{7}{|l|}{ Late rice } \\
\hline Control & $91.67 \mathrm{c}$ & $226.67 \mathrm{c}$ & $22.77 \mathrm{~b}$ & $140.33 \mathrm{~b}$ & $73.13 \mathrm{a}$ & $27.47 \mathrm{a}$ \\
\hline $0.00 \% \mathrm{NBPT}$ & $96.33 \mathrm{ab}$ & $200.00 \mathrm{~d}$ & $22.89 \mathrm{~b}$ & $158.00 \mathrm{ab}$ & $75.87 \mathrm{a}$ & $26.69 \mathrm{a}$ \\
\hline $0.50 \% \mathrm{NBPT}$ & $92.67 \mathrm{bc}$ & $229.33 \mathrm{c}$ & $24.24 \mathrm{ab}$ & $165.33 \mathrm{a}$ & $72.69 \mathrm{a}$ & $28.17 \mathrm{a}$ \\
\hline $075 \%$ NBPT & $95.67 \mathrm{ab}$ & $277.33 \mathrm{~b}$ & $23.72 \mathrm{ab}$ & $170.50 \mathrm{a}$ & $74.66 \mathrm{a}$ & $26.91 \mathrm{a}$ \\
\hline $1.00 \% \mathrm{NBPT}$ & $99.00 \mathrm{a}$ & $312.00 \mathrm{a}$ & $24.52 \mathrm{a}$ & $159.00 \mathrm{ab}$ & $77.71 \mathrm{a}$ & $27.62 \mathrm{a}$ \\
\hline $1.25 \% \mathrm{NBPT}$ & $95.00 \mathrm{bc}$ & $275.33 \mathrm{~b}$ & $23.77 \mathrm{ab}$ & $153.00 \mathrm{ab}$ & $76.16 \mathrm{a}$ & $28.02 \mathrm{a}$ \\
\hline $1.50 \% \mathrm{NBPT}$ & $93.67 \mathrm{bc}$ & $226.00 \mathrm{c}$ & $23.12 \mathrm{ab}$ & $146.00 \mathrm{ab}$ & $72.00 \mathrm{a}$ & $26.96 \mathrm{a}$ \\
\hline
\end{tabular}

Note: Data within a column followed by different letters for early or late rice differ significantly among all treatments at $P<0.05$ (with LSD test). Control was no NBPT or urea; $0.00 \%$ NBPT, $0.50 \%$ NBPT, $0.75 \%$ NBPT, $1.00 \%$ NBPT, $1.25 \%$ NBPT and $1.50 \%$ NBPT indicate that NBPT was applied at a rate of $0.00 \%, 0.50 \%, 0.75 \%$, $1.00 \%, 1.25 \%$ and $1.50 \%$ on a urea basis $\left(135 \mathrm{~kg} \mathrm{~N} \cdot \mathrm{hm}^{-2}\right)$.

Table 2 The exponential regression of NDVI at key growth stages against grain yield of rice

\begin{tabular}{lllll}
\hline Growth stages & Early rice & $R^{2}$ & Late rice & $R^{2}$ \\
\hline Tillering & $\mathrm{y}=6.37 \exp (0.83 \mathrm{x})$ & 0.55 & $\mathrm{y}=5.94 \exp (1.06 \mathrm{x})$ & 0.70 \\
Jointing & $\mathrm{y}=3.42 \exp (2.05 \mathrm{x})$ & 0.63 & $\mathrm{y}=4.02 \exp (2.15 \mathrm{x})$ & 0.62 \\
Heading & $\mathrm{y}=4.43 \exp (2.01 \mathrm{x})$ & 0.69 & $\mathrm{y}=6.09 \exp (1.46 \mathrm{x})$ & 0.63 \\
Filling & $\mathrm{y}=5.56 \exp (1.19 \mathrm{x})$ & 0.34 & $\mathrm{y}=7.40 \exp (0.88 \mathrm{x})$ & 0.49 \\
\hline
\end{tabular}


$0.49-0.70$ in late rice. This showed that NDVI was directly related to grain yield at key growth stages, and there were no significant difference across all key stages. Therefore, it was feasible to estimate rice yield at different rates of urease inhibitor based on NDVI.

In a validation experiment, there was minimal difference between measured and estimated values of grain yield based on NDVI at the heading stage both in early and late rice (Table 3 ). Their RMSE were 0.77 and 0.87 , so NDVI could predict grain yield of early and late rice at the heading stage using the regression equations in Fig. 3 and Fig. 4.
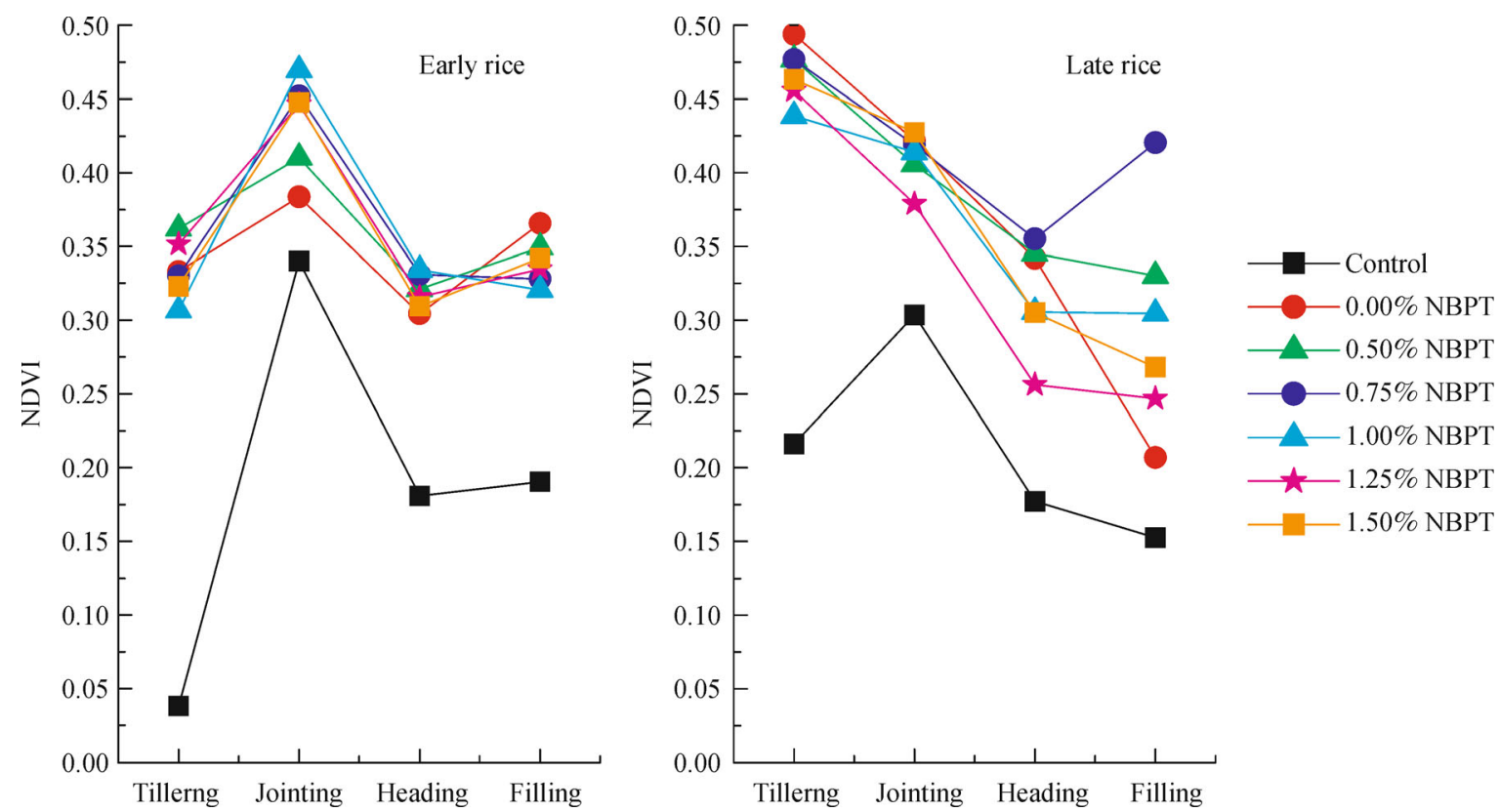

Fig. 2 The trend in NDVI at key growth stages of rice over a range of concentrations of the urease inhibitor NBPT in conjunction with urea application. The meaning of abbreviations for each treatment is indicated in the text: Control was no NBPT or urea; $0.00 \%$ NBPT, $0.50 \%$ NBPT, $0.75 \%$ NBPT, $1.00 \%$ NBPT, $1.25 \%$ NBPT and $1.50 \%$ NBPT indicate that NBPT was applied at rate of $0.00 \%, 0.50 \%$, $0.75 \%, 1.00 \%, 1.25 \%$ and $1.50 \%$ on a urea basis $\left(135 \mathrm{~kg} \mathrm{~N} \cdot \mathrm{hm}^{-2}\right)$.

Table 3 Analysis of the differences between grain yield in rice predicted from NDVI and actual yield in the validation experiment

\begin{tabular}{|c|c|c|c|c|c|c|}
\hline \multirow{2}{*}{ Treatments } & \multirow{2}{*}{$\begin{array}{c}\text { NDVI at } \\
\text { heading stage }\end{array}$} & \multicolumn{2}{|c|}{ Grain yield $/\left(\mathrm{t} \cdot \mathrm{hm}^{-2}\right)$} & \multirow{2}{*}{$\begin{array}{l}\text { Range error } \\
\text { ratio }\end{array}$} & \multirow{2}{*}{$R^{2}$} & \multirow{2}{*}{$\begin{array}{c}\text { RMSE } \\
/\left(\mathrm{t} \cdot \mathrm{hm}^{-2}\right)\end{array}$} \\
\hline & & Estimated value & Measured value & & & \\
\hline \multicolumn{7}{|l|}{ Early rice } \\
\hline Vcontrol & 0.210 & 6.760 & 6.680 & -0.012 & 0.457 & 0.774 \\
\hline V0.00\% NBPT & 0.237 & 7.130 & 8.380 & 0.176 & & \\
\hline V0.50\% NBPT & 0.248 & 7.300 & 8.310 & 0.139 & & \\
\hline V1.00\% NBPT & 0.273 & 7.660 & 8.510 & 0.111 & & \\
\hline V1.50\% NBPT & 0.263 & 7.510 & 7.510 & 0.000 & & \\
\hline V2.00\% NBPT & 0.225 & 6.960 & 7.470 & 0.073 & & \\
\hline \multicolumn{7}{|l|}{ Late rice } \\
\hline Vcontrol & 0.153 & 7.610 & 7.660 & 0.007 & 0.332 & 0.870 \\
\hline V0.00\% NBPT & 0.335 & 9.940 & 8.700 & -0.124 & & \\
\hline V0.50\% NBPT & 0.284 & 9.220 & 10.360 & 0.123 & & \\
\hline V1.00\% NBPT & 0.306 & 9.510 & 10.550 & 0.109 & & \\
\hline V1.50\% NBPT & 0.327 & 9.820 & 9.660 & -0.016 & & \\
\hline $\mathrm{V} 2.00 \% \mathrm{NBPT}$ & 0.285 & 9.230 & 8.440 & -0.085 & & \\
\hline
\end{tabular}

Note: Vcontrol was no nitrogen fertilizer and no NBPT both in early and late rice; V0.00\% NBPT, V0.50\% NBPT, V1.00\% NBPT, V1.50\% NBPT and V2.00\% NBPT were applied by $135 \mathrm{~kg} \cdot \mathrm{hm}^{-2}$ nitrogen fertilizer with $0.00 \% \mathrm{NBPT}, 0.50 \% \mathrm{NBPT}, 1.00 \% \mathrm{NBPT}, 1.50 \% \mathrm{NBPT}, 2.00 \%$ NBPT in early and late rice. 


\section{Discussion}

NBPT is often used as an additive to fertilizer used in agriculture. It can reduce urease activity, slow down the hydrolysis of urease decomposition, prolong urease diffusion time and decrease the concentration of ammonia present near the soil surface, and thereby improve $\mathrm{N}$ use efficiency and crop yield [3-5]. In this study, rice yield increased significantly when urea was applied with NBPT. The highest grain yield was observed with addition of $1.00 \%$ NBPT. This result was consistent with previous studies $[9,17]$.

NDVI measurement has been applied to diagnose nutrient (particularly $\mathrm{N}$ ) status during the growth and development of many crops, including rice and wheat $[18,19]$. Also, one study found that yield could be predicted by NDVI measured at key stages [20]. Yao et al. found that in-season estimates of yield calculated with GreenSeeker NDVI and RVI could account for $42 \%$ yield potential [21]. In that study, NDVI values are quite low compared to other studies [13,22,23], because the incident light and temperatures differed between the localities and because the rates of $\mathrm{N}$ fertilizer applied were also different. In Fig. 2, NDVI at key growth stages of rice was higher than the control, but there was no
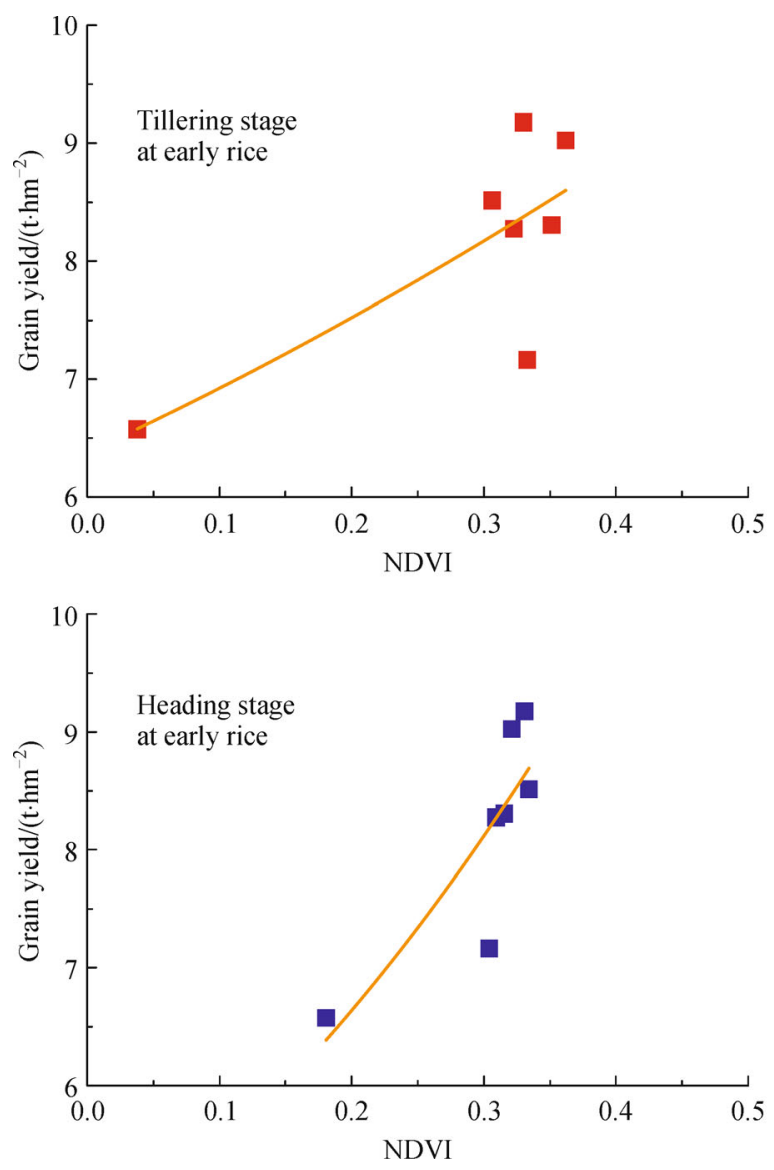

significant difference across the NBPT treatments. It is concluded that the effect of NBPT was not adequately indicated by NDVI at key growth stages of rice.

Many studies suggest that biomass, $\mathrm{N}$ accumulation and LAI in rice can be predicted with NDVI $[19,24]$. Inman et al. reported that NDVI could estimate grain yield in irrigated maize [12] and it is feasible that canopy NDVI at late-filling stage can predict yield of winter wheat [20]. Teal et al. found that there is a strong relationship $\left(R^{2}=\right.$ 0.77 ) between NDVI and grain yield in the V8 leaf stage of maize, but not at other leaf stages [25]. Xue et al. found that uptake of nitrogen and yield in rice were positively correlated with NDVI at the tillering and panicle initiation stages, and a spectrally-determined $\mathrm{N}$ topdressing model was established and successfully applied in early rice [26]. However, in this study, the grain yield of rice could be predicted based NDVI at all key growth stages by exponential equation, and their RMSE values were 0.77 and 0.87 . Therefore, grain yield in early and late rice could be predicted by NDVI, because the grain yield is closely related to aboveground biomass. Chang et al. reported that multiple regression models successfully predicted rice yield using canopy reflectance measured at the booting stage, unless other severe stresses occurred after that stage [27]. Optimized NDVI for each growth stage
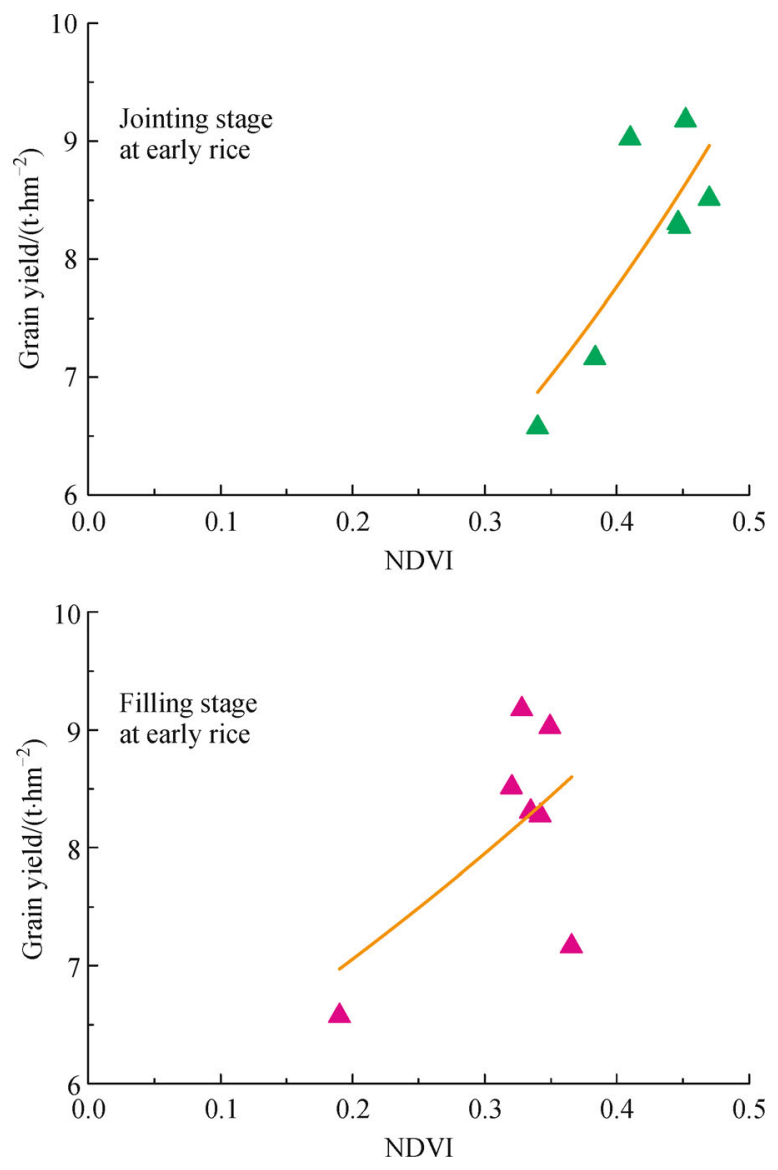

Fig. 3 The relationship between NDVI and grain yield of early rice at key growth stages 

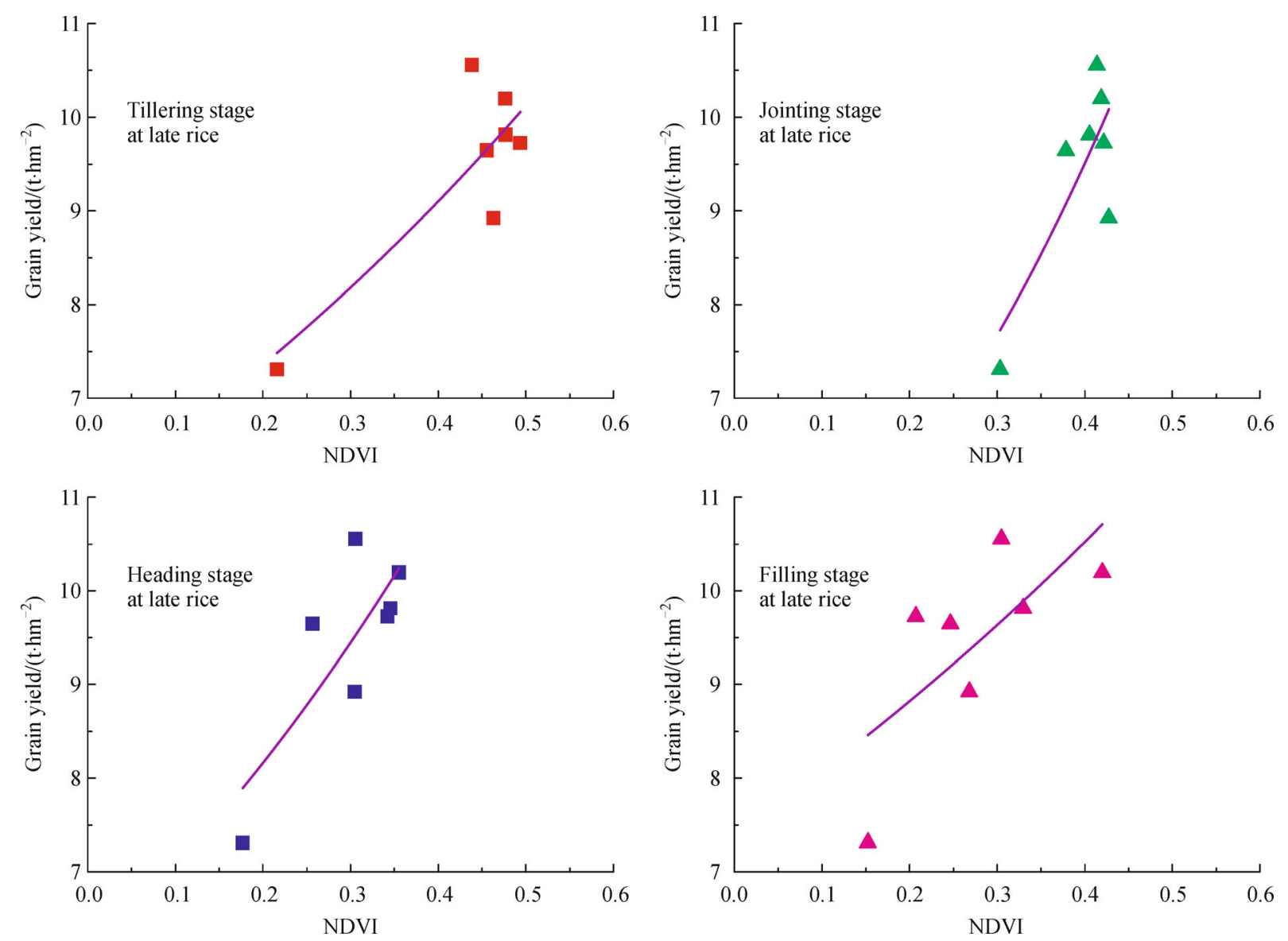

Fig. 4 The relationship between NDVI and grain yield of late rice at key growth stages

$\left(R^{2}=0.34-0.69\right)$ explains $18 \%-26 \%$ more variability in aboveground biomass [23]. But authors of other studies have argued that this is not possible and the differences between NDVI for different $\mathrm{N}$ treatments are strongly related to the vegetation canopy bidirectional reflectance factor effects [16]. Therefore, these regression equations need to be further tested, bearing in mind the fact that NDVI is only one kind of vegetation index, and that it may not sufficiently reflect the factors affecting yield of rice.

\section{Conclusions}

Grain yield of rice increased significantly when urea was applied with NBPT, and the greatest response was observed with a urea to urease inhibitor ratio of $1 \%$. Rice yield could be effectively predicted from NDVI values taken at key growth stages for both early and late rice, with no significant difference between these stages.

Acknowledgements This research was supported by Special Fund for Agro-scientific Research in the Public Interest (201203030 and 201003016), the National Basic Research Program of China (2011CB100501-S06) and Jiangxi Science and Technology Support plan (20141BBF60050). The authors thank Mr. Chungen Wang of the Jiangxi Institute of Red Soil for provision of the experimental site and facilities.

Compliance with ethics guidelines Kailou Liu, Yazhen $\mathrm{Li}$ and Huiwen $\mathrm{Hu}$ declare that they have no conflict of interest or financial conflicts to disclose.

This article does not contain any studies with human or animal subjects performed by any of the authors.

\section{References}

1. Ju X T, Xing G X, Chen X P, Zhang S L, Zhang L J, Liu X J, Cui Z L, Yin B, Christie P, Zhu Z L, Zhang F S. Reducing environmental risk by improving $\mathrm{N}$ management in intensive Chinese agricultural systems. Proceedings of the National Academy of Sciences of the United States of America, 2009, 106(9): 3041-3046

2. Akiyama H, McTaggart I P, Ball B C, Scott A. $\mathrm{N}_{2} \mathrm{O}$, NO, and $\mathrm{NH}_{3}$ emissions from soil after the application of organic fertilizers, urea and water. Water, Air, and Soil Pollution, 2004, 156(1): 113-129

3. Freney J R, Keerthisinghe D, Chaiwanakupt G, Phongpan P S. Use of urease inhibitors to reduce ammonia loss following application of urea to flooded rice fields. Plant and Soil, 1993, 155-156(1): 371-373

4. Rawluk C D L, Grant C A, Racz G J. Ammonia volatilization from soils fertilized with urea and varying rates of urease inhibitor NBPT. Canadian Journal of Soil Science, 2001, 81(2): 239-246 
5. Kawakami E M, Oosterhuis D M, Snider J L, Mozaffari M. Physiological and yield responses of field-grown cotton to application of urea with the urease inhibitor NBPT and the nitrification inhibitor DCD. European Journal of Agronomy, 2012, 43: $147-154$

6. Ding W X, Yu H Y, Cai Z C. Impact of urease and nitrification inhibitors on nitrous oxide emissions from fluvo-aquic soil in the North China Plain. Biology and Fertility of Soils, 2011, 47(1): 91-99

7. Dawar K, Zaman M, Rowarth J S, Blennerhassett J, Turnbull M H. Urease inhibitor reduces $\mathrm{N}$ losses and improves plant-bioavailability of urea applied in fine particle and granular forms under field conditions. Agriculture, Ecosystems \& Environment, 2011, 144(1): 41-50

8. Buresh R J, De Datta S K, Padilla J L, Samson M I. Field evaluation of two urease inhibitors with transplanted lowland rice. Agronomy Journal, 1988, 80(5): 763-768

9. Buresh R J, De Datta S K, Padilla J L, Samson M I. Effect of two urease inhibitors on floodwater ammonia following urea application to lowland rice. Soil Science Society of America Journal, 1988, 52 (3): $856-861$

10. Das D K, Mishra K K, Kalra N. Assessing growth and yield of wheat using remotely-sensed canopy temperature and spectral indices. International Journal of Remote Sensing, 1993, 14(17): 3081-3092

11. Ma B L, Morrison M J, Dwyer M L. Canopy light reflectance and field greenness to assess nitrogen fertilization and yield of maize. Agronomy Journal, 1996, 88(6): 915-920

12. Inman D, Khosla R, Reich R M, Westfall D G. Active remote sensing and grain yield in irrigated maize. Precision Agriculture, 2007, 8(4-5): 241-252

13. Harrell D L, Tubaña B S, Walker T W, Phillips S B. Estimating rice grain yield potential using normalized difference vegetation index. Agronomy Journal, 2011, 103(6): 1717-1723

14. Saberioon M M, Amin M S M, Aimrun W, Anuar A R, Gholizadeh A. Multi-spectral images tetracam agriculture digital camera to estimate nitrogen and grain yield of rice at different growth stages. Philippine Agricultural Scientist, 2013, 96(1): 108-112

15. Chen Q, Tian Y, Yao X, Cao W, Zhu Y. Comparison of five nitrogen dressing methods to optimize rice growth. Plant Production Science, 2014, 17(1): 66-80

16. Knyazikhin Y, Schull M A, Stenberg P, Mõttus M, Rautiainen M, Yang Y, Marshak A, Latorre Carmona P, Kaufmann R K, Lewis P, Disney M I, Vanderbilt V, Davis A B, Baret F, Jacquemoud S,
Lyapustin A, Myneni R B. Hyperspectral remote sensing of foliar nitrogen content. Proceedings of the National Academy of Sciences of the United States of America, 2013, 110(3): E185-E192

17. Pang G B, Peng S Z. Research advances of nitrogen fertilizer application technologies in Chinese rice field. Soils, 2010, 42(3): 329-335 (in Chinese)

18. Li H, Zheng L, Lei Y, Li C, Liu Z, Zhang S. Estimation of water consumption and crop water productivity of winter wheat in North China Plain using remote sensing technology. Agricultural Water Management, 2008, 95(11): 1271-1278

19. Zhu Y, Tian Y, Yao X, Liu X, Cao W. Analysis of common canopy reflectance spectra for indicating leaf nitrogen concentrations in wheat and rice. Plant Production Science, 2007, 10(4): 400-411

20. Wang L, Bai Y L, Lu Y L, Wang H, Yang L P. Yang L P. NDVI analysis and yield estimation in winter wheat based on GreenSeeker. Acta Agronomica Sinica, 2012, 38(4): 747-753 (in Chinese)

21. Yao Y, Miao Y, Jiang R, Khosla R, Gnyp M L, Bareth G. Evaluating different active crop canopy sensors for estimating rice yield potential. In Agro-Geoinformatics 2013 Second International Conference on. IEEE, 2013, 538-542.

22. Yao Y K, Miao Y X, Huang S Y, Gao L, Ma X B, Zhao G M, Jiang R F, Chen X P, Zhang F S, Yu K, Gnyp M L, Bareth G, Liu C, Zhao L, Yang W, Zhu H M. Active canopy sensor-base d precision N management strategy for rice. Agronomy for Sustainable Development, 2012, 32: 925-933

23. Gnyp M L, Miao Y, Yuan F, Ustin S L, Yu K, Yao Y, Huang S Y, Bareth G. Hyperspectral canopy sensing of paddy rice aboveground biomass at different growth stages. Field Crops Research, 2014, 155: $42-55$

24. Zhou L Q, Shi Z, Tian Y F. Rapid estimation of rice canopy LAI using multi-source proximal sensors. Precision Agriculture, 2013, 13: $87-93$

25. Teal R K, Tubana B, Girma K, Freeman K W, Arnall D B, Walsh O, Raun W R. In-season prediction of corn grain yield potential using normalized difference vegetation index. Agronomy Journal, 2006, 98(6): 1488-1494

26. Xue L H, Li G H, Qin X, Yang L Z, Zhang H. Topdressing nitrogen recommendation for early rice with an active sensor in south China. Precision Agriculture, 2014, 14: 1-16

27. Chang K W, Shen Y, Lo J C. Predicting rice yield using canopy reflectance measured at booting stage. Agronomy Journal, 2005, 97 (3): $872-878$ 